\title{
TRATAMIENTO MEDIÁTICO DE LA ENFERMEDAD EMERGENTE DEL ZIKA EN LA PRENSA ESCRITA
}

\section{THE JOURNALISTIC TREATMENT OF EMERGING ZIKA DISEASE IN THE PRESS}

\section{MARÍA DEL CARMEN CEVAllos ${ }^{1}$}

Recibido 12 de enero de 2017 Aceptado: 6 de marzo de 2017

\footnotetext{
${ }^{1}$ Pontificia Universidad Católica del Ecuador, Facultad de Comunicación Lingüística y Literatura, Escuela de ComunicaciónQuito, Ecuador (MCECEVALLOS@puce.edu.ec).
} 



\title{
TRATAMIENTO MEDIÁTICO DE LA ENFERMEDAD EMERGENTE DEL ZIKA EN LA PRENSA ESCRITA
}

\section{THE JOURNALISTIC TREATMENT OF EMERGING ZIKA DISEASE IN THE PRESS}

\author{
María del Carmen Cevallos
}

PALABRAS CLAVE: análisis de contenido, prensa escrita, Ecuador, Zika

KEY WORDS: content analysis, print media, Ecuador, Zika

\section{RESUMEN}

El estudio se enfocó en identificar el tratamiento periodístico de la enfermedad emergente del Zika en dos diarios del Ecuador. El virus del ZIKA fue el causante de una nueva epidemia que afectó a varios países de América Latina en especial a Brasil y Colombia por el alto número de infectados. Entre octubre de 2015 y marzo de 2016 se analizaron los diarios ecuatorianos "El Universo" y "El Comercio". Se utilizó la técnica del análisis de contenido y se observaron algunas variables como: espacio publicado, géneros periodísticos, jerarquización de la información; las voces/actores que intervinieron en la construcción de los mensajes, presencia de científicos en la elaboración de la información, entre otras variables. Los resultados muestran que la evolución de la información estuvo asociada al ciclo episódico del virus. El tema en general no mereció las portadas de los diarios, pese a la gravedad de la epidemia, ocupó espacios secundarios. El encuadre más utilizado fue el preventivo-educativo y se aprecia una ausencia de los científicos para la elaboración de la información. 


\section{ABSTRACT}

The study focused on identifying the journalistic treatment of emerging Zika disease in two newspapers of Ecuador. ZIKA virus was the cause of a new epidemics that affected several countries of Latin America, especially Brazil and Colombia due to the high number of infected individuals. Ecuadorian newspapers El Universo and El Comercio were analyzed between October 2015 and March 2016. The technique of content analysis was used and some variables such as journalistic genres, hierarchization of information; voices/actors that intervened in the construction of messages, and the presence of scientists in the elaboration of information, among other variables, were observed. The results show that the evolution of information was related to the episodic cycle of the virus. In general, the topic did not appear on the newspaper convers. Despite the seriousness of the epidemics, it was assigned secondary sections. The most common framing was preventive and educational. Scientists were absent from elaboration of information.

\section{INTRODUCCIÓN}

El virus del ZIKA transmitido por el mosquito Aedes aegypti es el causante de una nueva epidemia que afectó a varios países de América Latina en especial a Brasil y Colombia por el alto número de infectados. En el año 2014 el Zika llega a América, específicamente a la Isla de Pascua, donde se tuvo un caso, posteriormente llegó a Brasil $(14,16)$ aunque los científicos no saben con certeza cuál es el origen del brote que afecta de manera importante a este país y que se ha extendido por América Latina (Maguina, 2016).

En 2015 se reportan los primeros casos autóctonos de la enfermedad en el país más grande de América Latina y, en noviembre del mismo año la Secretaría de Salud (SSA) de México, reportó el primer caso de ZIKV importado en un viajero procedente de Santa Martha, Colombia (Torres, 2016).

En Ecuador, el Ministerio de Salud Pública informó que los dos primeros casos importados del virus de Zika fue el de dos ciudadanos ecuatorianos que habían estado en Neiva, Colombia y cuyo diagnóstico fue confirmado por el Instituto Nacional de Investigación Pública (MSP, 2016). 
De acuerdo con la información oficial del ente rector de salud pública en el Ecuador, al mes de octubre de 2016, en el país se reportaron 2.653 casos confirmados por exámenes laboratorio que determinan la infección por el virus del Zika.

\section{Tabla 1}

\section{Casos CONFIRMADOS autóctonos e importados de ZIKAV}

Ecuador hasta la SE 42,2016

\begin{tabular}{|l|c|c|c|}
\hline & Autóctono & Importado & Total general \\
\hline MANABí & 2.241 & 1 & 2.242 \\
\hline ESMERALDAS & 194 & & 194 \\
\hline GUAYAS & 103 & 1 & 104 \\
\hline SANTO DOMINGO & 39 & & 39 \\
\hline PICHINCHA & 23 & 12 & 35 \\
\hline LOS RÍOS & 18 & 1 & 19 \\
\hline EL ORO & 10 & & 10 \\
\hline SUCUMBÍOS & 4 & & 4 \\
\hline GALÁPAGOS & 2 & & 2 \\
\hline AZUAY & 1 & & 1 \\
\hline CHIMBORAZO & 1 & & 1 \\
\hline IMBABURA & 1 & & 1 \\
\hline ORELLANA & 1 & & 2.653 \\
\hline TOTAL & 2.638 & & 15 \\
\hline
\end{tabular}

Los 15 casos importados, reportan antecedente de viaje a Colombia y a Venezuela. Fecha de reporte: 26 de octubre de 2016,14h00. Fuente: (Ministerio de Salud Pública, 2016)

Las provincias de la costa ecuatoriana fueron las más afectadas: Manabí, Esmeraldas, Guayas y Santo Domingo de los Tsáchilas además de Pichincha ubicada en la sierra y que es la capital del país. Es en este contexto, que organismos internacionales como la Organiza- ción Mundial de la Salud, OMS y la Organización Panamericana de la Salud, OPS y los entes nacionales dieron la alerta del nuevo virus por lo cual adelantaron políticas públicas tendientes a contener la epidemia con base en la prevención uno de cuyos componentes fundamen- 
tales es la provisión de información a la población.

Son los medios de comunicación tradicionales y los nuevos medios los grandes aliados de las organizaciones gubernamentales y ONGs para informar a los ciudadanos quienes conforman el eslabón final de la cadena informativa y de hecho, juegan un importante rol activo para hacer frente a la epidemia. (Moreno, 2010).

Tampoco hay duda que la información emitida por los medios de comunicación puede promover la formación en salud dado que una epidemia como la del virus Zika es nueva en el país y requiere de un flujo informativo constante para familiarizar a las personas con el origen, las formas de contagio de la enfermedad, la evolución y sobre todo, las formas de prevenirlo enfocadas en aquellas poblaciones vulnerables.

Una de las formas de tener éxito con información de este tipo es poner en práctica la divulgación científica, dado que los periodistas trabajan con plazos muy apretados. La misma naturaleza del periodismo implica que se "hagan malabarismos" para lograr sacar a tiempo sus reportes. Conseguir fuentes para un reportaje de un tema como este que incluya a científicos es una tarea difícil y por lo tanto superar estos obstáculos mostrando el ángulo de relevancia y atención es lo que permitirá mantener la atención de los lectores (Joubert, 2004)

Por ello, en este estudio se trata de responder a la pregunta central ¿Cómo los diarios de mayor circulación e importancia en el Ecuador abordaron periodísticamente el tema del virus del Zika? Al ser un tema técnico y científico se quiere conocer si los científicos son consultados para la elaboración de la información y si dicha información es contextualizada y comunicada para que sea comprendida por los lectores $y$, eventualmente puedan poner en práctica las medidas de prevención y los comportamientos recomendados en sus discursos.

El interés actual por la salud ha crecido en los medios de comunicación, esto debido a que es noticiable y también porque su campo está vinculado a la lógica comercial de las empresas periodísticas ya que enganchar a las audiencias y lectores es atractiva para la publicidad.

La publicidad sobre salud mueve inversiones importantes de dinero en las que sobresalen las inversiones de poderosos anunciantes como las empresas farmacéuticas, compañías de seguros privados, y obras sociales del Estado y sindicatos... Asimismo, hay una variedad de actores interesados 
en convertir la información sobre salud en noticia (Waisbord, 2011).

Este estudio es una primera aproximación para comprender la forma cómo dos medios impresos del Ecuador, de carácter nacional y de amplia circulación trataron el tema desde lo periodístico.

La enfermedad del Zika tuvo su origen en 1947 y fue descubierta cuando se realizaban estudios de la fiebre amariIla en los monos Rhesus en los bosques de Uganda. En 1954 se publicó sobre los primeros casos de infecciones por el virus en Nigeria considerándose en primera instancia eran de fiebre amarilla (Viñuela Benéitez, 2016). En 1958 logran aislar por primera vez vez el virus en humanos en Nigeria y desde esa fecha hasta 2007, de forma esporádica se han registrado 14 casos de infección por el virus Zika, el cual circula en diversas áreas de Africa y en el Pacífico. Es en Micronesia, fuera de Africa y Asia, donde en el mismo año se produce el primer brote. Entre 2013 y 2014 la presencia del virus se advierte en la Polinesia Francesa, Nueva Caledinia, islas Salomón, Samoa e Isla de Pascua (Viñuela Benéitez, 2016).

En febrero de 2015 Brasil es el país que da la alerta con un brote de transmisión autóctona del virus el mismo que es confirmado en mayo del mismo año. En septiembre Colombia informa de la transmisión viral y desde el mes de noviembre la epidemia se ha multiplicado por todos los países latinoamericanos.

Según la Organización Panamericana de la Salud y la Organización Mundial de la Salud OMS/OPS, hasta noviembre de 2016"48 países/territorios de las Américas confirmaron casos autóctonos por transmisión vectorial del virus del Zika y cinco países notificaron casos de Zika transmitidos sexualmente" (OPS/ OMS, 2016) 


\section{Tabla 2}

\section{Situación epidemiológica del Zika por subregiones}

\begin{tabular}{|l|l|l|l|}
\hline SUBREGIONES & PAíS & SEMANA EPIDEMIOLÓGICA & SITUACIÓN \\
\hline América del Norte & México & 39 & Decreciente \\
\cline { 2 - 4 } & Estados Unidos & Sin números & $\begin{array}{l}\text { Se siguen detectando casos autóctonos } \\
\text { en la zona de Miami Beach y el Condado } \\
\text { Miami Dade }\end{array}$ \\
\hline América Central & Panamá & & Tendencia creciente \\
\hline Caribe & Monserrat (Caribe) & $36-41$ & Circulación autóctona del virus \\
\hline \multirow{2}{*}{ América del Sur } & Islas Turcas y Caicos (Caribe) & 36 y 38 & Tendencia creciente \\
\hline & Perú & 37 & Tendencia creciente (lquitos) \\
\hline & Brasil & 7 y 9 & El mayor número de casos \\
\hline
\end{tabular}

Fuente: (OPS/OMS, 2016)

En la región de América Latina los países más afectados fueron Brasil y Colombia. En el caso del primero por su extensión propia, alcanzó la cifra 200.465 casos sospechosos, 109.596 casos confirmados y 2.143 casos congénitos asociados al síndrome por infección del virus Zika. En Colombia los casos sospechosos fueron 96.421 mientras que los confirmados llegaron a 8.826 y 56 fueron asociados el síndrome congénito. Sin embargo, la isla caribeña de Puerto Rico registra un total de casos confirmados que llegan a los 33.455 . (PAHO/WHO, 2016).

Los datos muestran un alto impacto en los sistemas de salud de los países más afectados, ya que la epidemia se extendió rápidamente traspasando fronteras y afectando a poblaciones vulnerables que tienen condiciones de vida precarias asociadas a la infraestructura de los sistemas sanitarios. "Su posible asociación con microcefalia y síndrome de Guillain-Barré motivó que la Organización Mundial de la Salud (OMS) declarase el 1 de febrero de 2016 que esta epidemia constituye una emergencia de salud pública de importancia internacional" (J. A. Caylà, 2016) El virus Zika es transmitido por la picadura del mosquito Aedes que también está relacionado con las enfermedades del dengue y la chikungunya. (Viñuela Benéitez, 2016).

Esta nueva epidemia que tuvo un gran impacto mediático se produce luego de otras varias que también han afectado a las diversas regiones del mundo 
como el ébola que arreció en África. En el 2009 la primera pandemia de AH1N1 popularmente conocida como la "gripe porcina" generó serios desafíos para su tratamiento tanto a nivel clínico como para contener la misma en términos de prevención. En el 2014, Ecuador ingresó a la lista de los países afectados por el virus de la influenza al detectarse el primer caso confirmado por el Ministerio de Salud en el puerto de Guayaquil (Cevallos y Massarani, 2011).

Para los medios de comunicación la pandemia de la influenza constituyó un desafío ya que fue un tema nuevo para el tratamiento informativo dadas las características de la enfermedad ya que no había información certera de su origen ni de cómo se generaba el virus.

Los medios de comunicación tradicionales y los nuevos medios por lo general, son actores importantes de las crisis sanitarias dado el rol que se les asigna para emitir información que pueda apoyar las acciones de prevención en situaciones de crisis y riesgo.

El interés de los medios de comunicación por la salud no es nuevo, desde sus inicios dedicaron espacios, aunque no siempre en la dimensión que se requería, a informar sobre los avances médicos, los nuevos inventos, tratamientos novedosos y la prevención de las diversas enfermedades. Otros temas diferentes a salud como deportes o nota roja copaban las portadas de los diarios mientras que salud era relegada a páginas secundarias. (Loewy, 2011).

La técnica del análisis de contenido busca a través de una serie de procedimientos metodológicos interpretativos analizar los materiales comunicacionales ya sean textos, discursos o mensajes que han sido difundidos por los medios de comunicación tradicionales y los nuevos medios digitales para lo cual se utilizan técnicas cuantitativas o cualitativas. La primera para contabilizar unidades que luego serán estadísticas y las segundas "basadas en la combinación de categorías que tienen por objeto procesar datos relevantes sobre las condiciones mismas en que se han producido aquellos textos" (Piñuel, 2002).

Esta es una de las técnicas más usadas en las ciencias sociales desde finales del siglo pasado y que hoy en día cuentan con una serie de técnicas informatizadas que facilitan el trabajo de procesamiento de los datos. "su propia denominación de análisis de "contenido", lleva a suponer que el "contenido" está encerrado, guardado -e incluso a veces oculto -dentro de un "continente" (el documento físico, el texto registrado, etc.) y que analizando "por dentro" se puede develar su contenido" (Piñuel, 2002).

Se trata en este proceso que no es mecánico, comprender aquello que está latente, "escondido" para significar 
y resignificar aquello que no se dice y que se oculta. Por ello diversas son las variables y categorías que se usan para explicar la forma y el fondo de cómo se estructuran los mensajes en un determinado contexto social y a qué se atribuyen ciertos sentidos que buscan legitimar para incidir en los lectores.

La lógica de la producción noticiosa está asociada a la "importancia social" de los temas cuyos hechos deben ser atractivos para las audiencias y los lectores lo cual no siempre coincide con "aquello que (en teoría) más impacta en sus vidas"(Loewy, 2011). Esto implica que los criterios de inclusión/exclusión son claves al momento de decidir la publicación o no de una nota informativa.

Hay una clara incidencia de la agenda setting y de las políticas editoriales de los medios para decidir qué publicar y con qué criterios. Si bien hay criterios de la "noticiabilidad" de la información que se han usado desde los orígenes de la prensa en cuanto a destacar la utilidad social y la dimensión educativa de la misma para publicarla, no siempre se cumplen. Esto claramente tiene que ver con lo que algunos teóricos del periodismo han señalado "sobre los valores o atributos que aumentan la probabilidad de que un acontecimiento atraiga a los periodistas (y lectores) pase a transformarse en noticia y forme parte de la pauta de los medios" (Loewy, 2011).
Un estudio realizado en Argentina en 2006 da cuenta que la salud y la ciencia son contenidos importantes de los medios de comunicación en su agenda diaria y no solo como suplementos o material aislado sino como parte fundamental de su estructura periodística. Este es un fenómeno que desde la década de los 80 se ha profundizado y en una explicación es que las encuestas realizadas sobre preferencias por medios internacionales y organizaciones como el "Pew Center" en Estados Unidos muestran que los lectores cada vez están más interesados en información que les sea de utilidad y que les sirva para tomar decisiones asertivas en su vida (Polino et al, 2006).

Sin duda, en el Ecuador también hay avances en torno a incluir contenidos de salud y definir de políticas editoriales que tiendan a ofrecer información y servicios a los ciudadanos a través de sus medios. Es por ello que los mensajes relacionados con este campo cada vez son más evidentes en los diversos medios. Desde el lado científico se cuestiona el hecho de que la noticia sobre salud, que es el género periodístico más utilizado en el país, sea puntual, sesgada y con énfasis en acontecimientos coyunturales y que no tenga un seguimiento posterior lo cual incide en la calidad de la información y en su verdadera relevancia. (Loewy, 2011). 
Sin embargo, cuando se trata de una epidemia como la del virus Zika o en ocasiones pasadas la influenza o el ébola, es cierto que los medios despliegan más espacios para dar a conocer las condiciones, contexto y consecuencias de la enfermedad y en su mayoría, centrando su interés en la motivación hacia el cambio de comportamientos o adhesión a medidas de prevención para evitar el contagio de la enfermedad.

Uno de los vacíos detectados en los estudios realizados sobre la gripe AH1N1 en el Ecuador, (Cevallos y Massarani, 2011) es la falta de formación profesional de los periodistas para hacer divulgación científica, dado que esta actividad puede proveer a los ciudadanos información relevante, verificada, contrastada, con respaldo científico y en un lenguaje sencillo que les permita disponer de la información por distintos medios, canales y plataformas para usarla en el momento que lo requieran.

La cautela y la profundidad con la que se debe tratar el tema al momento de difundir información sensible no es tomada en cuenta. La especialización por lo tanto se vuelve clave y central para este tipo de episodios. Se observó que los científicos estaban ausentes de la construcción de la información y que el peso estaba en los actores políticos lo cual restaba credibilidad a la información.
Un aspecto que es central en la divulgación de información de salud es la relacionada con los sectores rurales o excluidos de los medios de comunicación o que no tienen acceso a las nuevas tecnologías. Es allí donde los medios deben buscar generar las estrategias para lograr que la información llegue a la gran mayoría de la población.

Las fuentes de información es un punto que genera tensión con los periodistas. "El concepto de noticia puede ser diferente para el periodista y para la fuente de la información". (Román, 2011). Para las autoridades de las instituciones públicas la relevancia de la información tiende a "exibir y a difundir exageradamente medidas sanitarias, como la compra de equipos y tienden a ocultar o minimizar hechos que no los favorecen políticamente". (Román, 2011). En el caso específico de la epidemia de la influenza el Ministerio de Salud de Ecuador decidió que no se publicaran los datos del número de contagiados, dado que en el periodo crítico de la crisis, los casos aumentaron rápidamente y eso creó un clima de incertidumbre y miedo en la población. Sin embargo, el mantener informada a la población es un derecho que según la forma de comunicar puede ser una oportunidad para transmitir seguridad y da señales de lo que las autoridades hacen por la población. 
Los representantes de instituciones públicas y privadas son consultadas mayormente sobre determinados temas de salud. Hoy en día hay una actitud de mayor colaboración y de generar puentes entre los distintos sectores que observan que los temas asociados a la salud, son indispensables para la toma de decisiones de los ciudadanos. Sin embargo, los mismos científicos ocupan lugares secundarios a la hora de elaborar las notas periodísticas, lo cual puede generar dudas sobre la credibilidad de la información, sobre todo cuando se trata de explicar aspectos técnicos y científicos de una enfermedad.

No hay duda que el impacto mediático de una informacion sobre una enfermedad o epidemia es mayor si tiene un sustento científico y que esté avalado por los argumentos del investigador.

Es cierto que las últimas epidemias sobre la influenza o gripe A, el ébola y recientemente el Zika han captado el interés del periodismo y han enfrentado a los mismos a serios desafios en torno a su cobertura por las dinámicas epidemiológicas específicas de cada enfermedad, "no hay duda de que la la atención mediática desbordó los cauces normales" (Waisbord, 2011). En gran parte esto se debe a que epidemias como las mencionadas tienen repercusiones en la sociedad por efecto del despliegue informativo mediático que, como en el caso de la "gripe A", implicaron generar consejos y comportamientos como medidas preventivas y de seguridad (excluir al beso social del saludo, mayor frecuencia en el lavado de las manos; estornudar en la manga) y a nivel masivo ciertas medidas que llevaron a suspender eventos masivos que implicaran ciertos riesgos de contagio.

Sin embargo, también se observó que la exposición mediática del tema "fuera responsable de decisiones personales (la estigmatización de ciudadanos mexicanos cuando se desencadenó la epidemia, la cancelación de viajes turísticos) y políticas (la prohibición de vuelos aéreos, el reforzamiento de sistemas de vigilancia". (Waisbord, 2011).

Las noticias sobre epidemias de salud suelen estar altamente asociadas al número de casos de contagiados/infectados y a mostrar permanentemente la "evolución" de la epidemia que finalmente construyen relatos de riesgo, crisis, miedo e incertidumbre.

Se confirmó esto cuando en el estudio realizado en el 2011 en Ecuador los propios periodistas al hacer la cobertura periodística del tema aparecían con mandiles y mascarillas generando en la población esa sensación de miedo al contagio. La información que por lo general se genera en las fuentes oficiales están directamente asociadas a los peligros reales de las epidemias y por lo 
tanto los medios usan encuadres interpretativos que acentúan el peligro.

La información se estructura de una manera determinada a fin de generar diversos sentidos. Los frames o recuadros en los medios de comunicación se concibieron como "la idea central organizadora del contenido noticioso, que proporciona un contexto, y sugiere en qué consiste el asunto, mediante la selección, el énfasis, la exclusión y la elaboración" (Tankard, 1991).

Esto significa que nada es espontáneo al elaborar la información ya que la selección de la información es incluir unos aspectos y excluir otros de un he- cho o una realidad y que bien pueden tener una intencionalidad al hacerlo. Así mismo el resaltar o hacer predominantes ciertos encuadres se está promoviendo una determinada forma de ver dicha realidad que se relata para que los lectores puedan darle una determinada interpretación sugerida por el texto y con la visión particular del periodista la cual puede estar influenciada por aspectos personales y profesionales con los cuales aborda la elaboración de los relatos (Sábada, 2008). Es decir, se trata de comprender desde qué ángulo o perspectiva los lectores deben interpretar o dar sentido a la información.

\section{OBJETIVOS}

\section{Objetivo general:}

Identificar el tratamiento periodístico que los diarios "El Comercio" y "El Universo" dieron al virus Zika en los meses de noviembre de 2015 a marzo de 2016.

\section{Objetivos específicos:}

Identificar el número de notas in- formativas publicadas sobre el virus Zika en los dos diarios.

Establecer el tipo de información predominante en los dos diarios sobre el virus Zika.

Determinar el framing utilizado en los diarios para elaborar la información sobre el virus Zika.

\section{MATERIALES Y MÉTODO}

El objeto de estudio estuvo constituido por los diarios "El Comercio" de la ciudad de Quito y "El Universo" de la ciudad de Guayaquil, los dos de circulación nacional y de amplia trayectoria en el contexto ecuatoriano. El periodo de 
análisis estuvo comprendido entre noviembre de 2015 fecha en que se declaró la alerta de salud en el país, hasta marzo de 2016. Esto obedeció a la necesidad de estudiar con urgencia la forma como los medios abordaron el tratamiento periodístico del virus Zika por la emergencia que se vivía en otros países, dada la coyuntura de ese momento.

\section{ANÂLISIS}

En el periodo comprendido entre noviembre de 2015 y marzo de 2016, los dos diarios publicaron un total de 71 notas informativas. Fue el rotativo costeño el que más publicó con 21 notas más. "El Universo" publicó más notas asumiendo que las provincias costeras son más vulnerables y podrían tener más afectados en parte debido al clima de esas zonas. Se considera que la epidemia está en directa relación con las condiciones de salubridad y de servicios básicos a los cuales los ciudadanos tienen acceso. La primera nota publicada por "El Universo" fue el 20 de octubre de 2015 con el título: Ministerio de Salud Pública emite alerta epidemiológica ante introducción de virus del Zika, información que está basada en la fuente de la Organización Panamericana de la Salud, OPS y que buscó generar en la población, precaución ante esta nueva amenaza sanitaria que se expandía a gran velocidad por el continente. "El Comercio" publica su primera nota el 22 de octubre con el título: Alerta epidemiológica ante la posibilidad de introducción del virus del Zika. La diferencia que encontramos en el tratamiento periodístico es que mientras el diario costeño publica apenas una reseña de un párrafo, el diario capitalino hace una nota informativa amplia, señalando los antecedentes del primer brote de la epidemia en Uganda, las causas, la forma de contagio y cómo la población puede prevenir. ("El Comercio", 2015). 
Gráfico n. ${ }^{0} 1$.

Evolución de la información sobre el virus Zika.

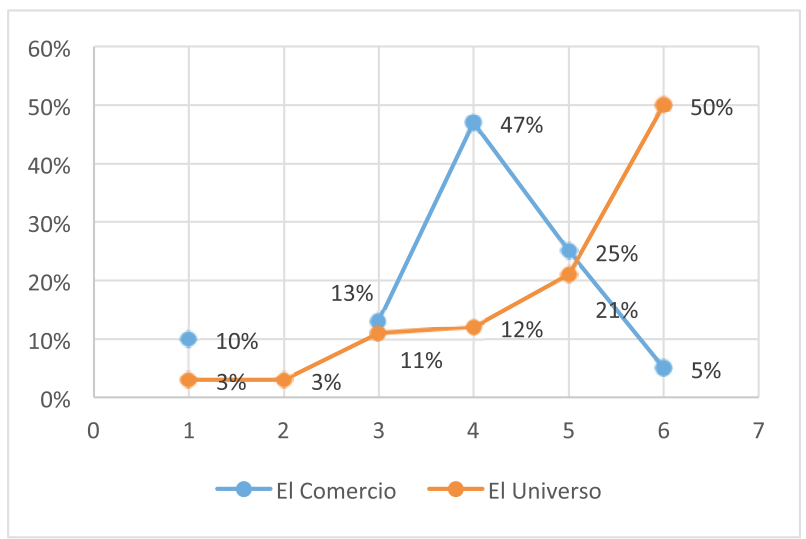

El despliegue en términos de espacio de la información publicada por los dos diarios responde a una necesidad emergente de la propagación del virus Zika en la región latinoamericana. En los medios de comunicación "... se diseñan de manera racional mensajes cuyo destino asignado consiste en modificar comportamientos, hábitos y percepciones sobre la base del cuerpo de conocimientos científicos". (Kaufman, 2011). Desde la perspectiva de la divulgación, una de las finalidades fundamentales de la información científica es acercar los conocimientos a los ciudadanos de forma sencilla, en un lenguaje que "enganche al lector y es preferible que se comience con una imagen de impacto (...) en fin, algo que sorprenda al lector". (Vieira, 2004)
Y eso es precisamente lo que hizo la prensa para llamar la atención y buscar esa empatía y proximidad con los lectores para seducirlos e interesarlos a que lean la información completa. Titulares como Zika, el nuevo enemigo o Investigadores brasileños encuentran virus del Zika en cerebros de bebés ("El Comercio", 2016); Zika, chikungunya y dengue tienen síntomas similares; En Manta, la primera infectada con Zika es una niña (El Universo, 2016) son una muestra de los titulares.

La información fue en forma ascendente. Conforme avanzaba la epidemia en países vecinos y se propagaba al Ecuador, los dos diarios incrementaron el flujo informativo. Es así como en el mes de febrero "El Universo" difundió el mayor número de notas ya que es en esta 
época donde el número de infectados por el virus aumentó y, acorde con ello la producción informativa, creció en paralelo. Nueve fueron las notas publicadas por el rotativo costeño y todas referidas a la relación entre microcefalia y el Zika en los bebés y que se originaron en otros países. Dan cuenta también de los estudios científicos que se adelantan para comprender y explicar la relación que hay entre el virus del Zika y la microcefalia en bebés y las consecuencias para los recién nacidos. Por su parte, "El Comercio" publica 12 notas en el mes de marzo que constituye el mes más productivo informativamente hablando.

Las notas periodísticas tienen como base información científica resultado de estudios que adelantan en países europeos y en Estados Unidos para confirmar la relación entre Zika y microcefalia en bebés, así como la posibilidad de contar con una vacuna contra el virus. De la misma manera destacan las consecuencias el hecho de que mujeres embarazadas contrajeran el virus y sus bebés nacieran con microcefalia.

El abordaje busca sustentar en datos técnicos y científicos a partir de estudios con el fin de dar mayor credibilidad a la información. "El Comercio" mantiene una línea de desarrollo de la información ascendente durante el período estudiado mientras que "El Universo" al encontrar el punto más alto en el mes de febrero empieza a decrecer su flujo informativo con una disminución sustantiva de notas periodísticas.

Se considera una excepción los cliclos "mediáticos-epidémicos" cuando están enfocados en la cobertura de una epidemia como la del Zika en la cual la información atraviesa tres fases: 1) ausencia o presencia limitada en secciones especiales; 2) duración prolongada y priorizacion en el ciclo del Zika y, 3) vuelta a cobertura mínima (Waisbord, 2011 pp.-187).

La innminente presencia de la epidemia alertaba de su peligro en el país, dada la cercanía con Colombia donde se registró un alto número de casos sospechosos; el torrente noticioso empezó a fluir y a ofrecer a los lectores información descriptiva del virus y siempre con recomendaciones y consejos para evitar su contagio. Posteriormente cuando el virus hizo presencia en el país, el aumento de las notas periodísticas se hizo evidente. En ellas los argumentos estuvieron vinculados al número de casos, declaraciones de autoridades y expertos así como a la evolución de la epidemia. Posteriormente la tercera etapa tuvo una tendencia a disminuir la información dado que la "noticiabilidad" pasó y fue opacada por otros temas de coyuntura.

"El Universo" publica en su gran mayoría información proveniente de 
fuentes internacionales. Las notas están relacionadas con hechos que ocurren en países como Brasil, Colombia y otros de fuera de América Latina, donde el virus tiene una presencia grande dada la compejidad de la epidemia por el número de infectados. Noticias como Primera vacuna del zika no estará lista antes de tres años según expertos, proviene de Ginebra donde se realizó un encuentro para observar avances de la investigación sobre el virus; Cuba reporta primer caso de zika transmitido en la isla y Estudio en Honduras halla 11 casos de Guillain-Barré asociados con el Zika son una muestra del tipo de información que este diario emite proveniente de fuera del país ("El Universo", 2016) "El Comercio" hace alusión a: Rusia controla entradas marítimas aéreas desde países con Zika; Chile confirma el primer contagio de zika por transmisión sexual; y Riesgo de microcefalia asociada al zika es del $14 \%$ en Brasil.("El Comercio", 2016).

Estas y otras informaciones provenientes del exterior dan cuenta de los estudios científicos que se adelantan para lograr una vacuna así como mostrar la situación que otros países enfrentan sobre este problema. Las informaciones son explicadas de manera que los lectores puedan comprender lo mejor posible dado que son datos técnicos los que son expuestos en estos casos.

Frente al peligro de expansión de la epidemia los medios alertan a la pobla- ción a prevenir la enfermedad. Proveen de información sobre lo que sucede en otros países para que los ciudadanos se sensibilicen y adopten medidas preventivas para impedir su propagación y puedan mirar en otras realidades las consecuencias de una epidemia como el Zika.

Los dos diarios utilizan como fuentes principales de información a agencias internacionales de noticias como EFE agencia internacional creada en España; AFP (Agencia Fran Press) de origen francés y DPA (Agencia Alemana de Prensa) en mínimo grado. La información relativa a estudios científicos del Zika ameritan el servicio de noticias de estas agencias que se encuentran en Europa y que tienen también corresponsales en todos los países del mundo ya que la investigación científica se desarrolla con más rapidez dados los recursos académicos, científicos y financieros que tienen a su alcance,. Es decir, el conocimiento también tiene su hegemonía en el norte y de allí procede la información de este tipo.

La información en los medios de comunicación tradicionales todavía está marcada por los temas considerados "duros" como son la política y economía. Son los que acaparan las portadas de los diarios en tanto que temas de salud no están con frecuencia en estas secciones sino que tienen una ubicación secundaria. Si bien la salud en los 
medios gana cada vez más espacio y se crean secciones fijas que muestran un interés creciente por el tratamiento del tema, todavía no logran una ubicación estelar, salvo en casos de tragedias o de epidemias donde fugazmente se ubican en las planas principales. El tema también tiene implicaciones de carácter económico. Intereses muy fuertes ligados a empresas corporativas sean de seguros de salud, farmacéuticas y el propio Estado tienen interés en que la salud esté presente en los medios de comunicación. A pesar del creciente interés como tema periodístico, es muy dificil que en las portadas de los diarios se observe entre los titulares información sobre salud (Waisbord, 2011).

"Por lo general, las noticias suelen estar limitadas a secciones especiales sin adquirir mayor atención o atracción temporal dentro del vertiginoso ciclo noticioso" (Waisbord, 2011) lo que quiere decir que es muy poco frecuente que aparezcan en las portadas de los diarios porque están predestinadas a otros temas de mayor "importancia". El número de notas que aparecen en portada no son representativas y pese a que en el marco de una epidemia que se inicia y que se prevé se expandirá rápidamente y, para la cual no se cuenta todavía con una vacuna, los medios actúan de manera coyuntural. Es decir, la representación que hacen de la información está sustentada en abarcar hechos coyunturales a exigencias de la realidad del momento. Si bien hay un cierto seguimiento no se observa una línea editorial que tienda a ofrecer información continua a los lectores para generar una cultura preventiva en salud. 


\section{Gráfico n. ${ }^{0} 2$}

\section{Presencia de científicos en la información sobre el virus Zika}

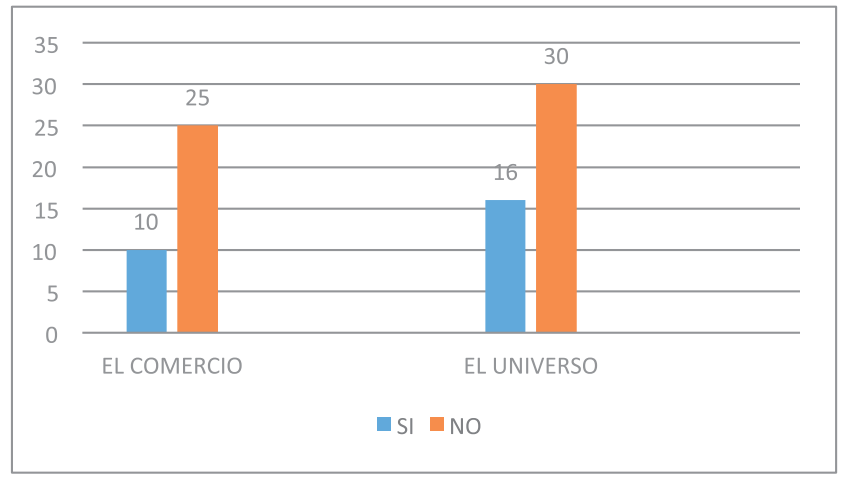

En los dos diarios se aprecia una ausencia importante de los científicos al construir la información sobre el Zika. En pocas piezas informativas, se incluyen a investigadores que dan su versión, puntos de vista o argumentos sobre la evolución de la epidemia o avances en torno a los estudios que se adelantan sobre esta nueva epidemia. Esta situación ya se observó en el estudio realizado en 2011 sobre el tratamiento de la pandemia de la gripe $\mathrm{A}(\mathrm{H} 1 \mathrm{~N} 1)$ (Cevallos y Massarani, 2011).

A diferencia del estudio anterior que usaban más fuentes oficiales, se ve que la representación que hacen de esta realidad está basada en varias fuentes y los redactores hacen un relato a manera de resumen de los datos, los organizan, sistematizan y busca ponerlos en un lenguaje sencillo. Sin embargo, en el ima- ginario de los lectores no está presente el valor que los científicos le agregan a la información y por ello, posiblemente confian en lo que el medio les da. Debería ser parte de los estándares de calidad periodística que los medios y los periodistas incluyan a los científicos como fuentes indispensables para la elaboración de información sobre salud y más aún, como en este caso cuando la máxima autoridad de la Organización Mundial de la Salud, OMS Margaret Chang ha señalado que "el virus del Zika es "un misterio" y que hay que profundizar los estudios sobre la posible relación con la microcefalia" ("El Comercio", 2016).

Es aquí donde los medios tienen que generar puentes de comunicación con las fuentes y en especial con los científicos para superar la subrepresentación que ellos tienen en los relatos periodís- 
ticos sobre el Zika. Esta subrepresentación de los científicos podría distorsionar la percepción y actitudes del público en torno a la credibilidad de la información.
"Al parecer las notas periodísticas tienen más un tinte político y humano que un enfoque científico técnico..." (Cevallos y Massarani, 2011).

Tabla n. ${ }^{0} 3$

Géneros periodísticos

\begin{tabular}{|l|c|c|c|c|}
\hline & \multicolumn{2}{|c|}{ EL COMERCI0 } & \multicolumn{2}{c|}{ EL UNIVERSO } \\
\hline Noticia & 10 & $40 \%$ & 34 & $74 \%$ \\
\hline Entrevista & 2 & $8 \%$ & 0 & $0 \%$ \\
\hline Reportaje & 6 & $24 \%$ & 3 & $7 \%$ \\
\hline Informe & 5 & $20 \%$ & 4 & $9 \%$ \\
\hline Corto & 2 & $8 \%$ & 5 & $11 \%$ \\
\hline Total & 25 & $100 \%$ & 45 & $100 \%$ \\
\hline
\end{tabular}

La dinámica de los medios de comunicación y la inmediatez con que la información circula en el mundo globalizado e hiperconectado de hoy, puede ser uno de los factores determinantes para que la noticia sea el género preferido en los medios. Es el género más sencillo de construir aun cuando hay lectores a los cuales "les gustaría encontrar en los medios mensajes más consolidados y sostenidos" (Loewy, 2015). En estudios anteriores realizados en el Ecuador se ha observado el excesivo uso del género noticia dejando en segundo plano a aquellos que ofrecen información con alta referencialidad y un conocimiento más profundo del tema basado en una pluralidad de fuentes además de poner a disposición del público datos que pueden ser de utilidad como enlaces o referencias a otras fuentes. La construcción de este género, en el caso específico del Zika incluye una narrativa de percepción de riesgo, del miedo así como también de consejos que buscan influir en la modificación de comportamientos de los ciudadanos a fin de promover prácticas para evitar situaciones de contagio o de graves consecuencias.

"El Comercio" usa el género reportaje que es el más completo, lo cual muestra una evolución en su práctica profesional por ofrecer a sus lectores otros formatos que les den la posibilidad de tener su propia opinión con base en los datos publicados. 
Cuando hay estudios científicos en proceso y, los resultados no son definitivos, los investigadores prefieren que no se divulguen. Por ello los reporteros acuden a la noticia rápida, factual debido a la presión de publicar sobre un acontecimiento que es parte de la agenda seting y que tiene su propia dinámica episódica mientras no hayan otros hechos que se superpongan a este. Géneros periodísticos como informe que está basado en una investigación a fondo sobre el tema y que incluye el uso de varios géneros periodísticos tiene una cierta representatividad y se aprecia el esfuerzo por incluir la investigación periodística como base del mismo.

\section{Gráfico n. ${ }^{\circ} 3$ \\ Tratamiento periodístico}

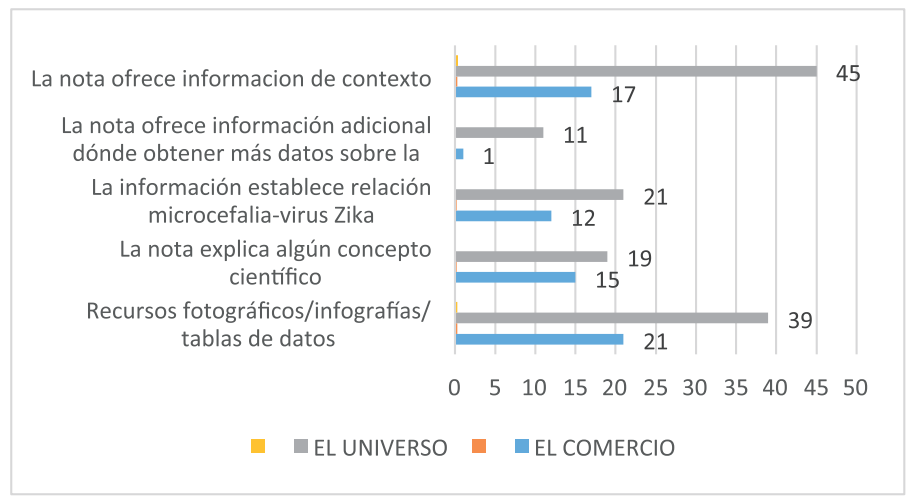

El caso de diario "El Universo" debido a que publicó mayor cantidad de notas, estas tienen información que contextualiza los hechos que se relatan. En temas de salud y de epidemias "trascienden las divisiones sociales y geográficas de otras enfermedades" (Waisbord, 2011). Los medios dan gran importancia a este tipo de noticias que no afectan a un determinado sector como el rural sino que poblaciones enteras pueden ser víctimas de una epidemia, y por ello al ser enfermedades relativamente nuevas, ofrecen más detalles y elementos que permitan acercarse a la misma para comprender su origen, evolución, formas de prevención, entre otros aspectos. Desde esta perspectiva, la información tiene alta referencialidad porque ofrecen detalles y datos de inte- 
rés y de uso social en la vida cotidiana de los ciudadanos.

Por su parte, "El Comercio" usó generosamente recursos gráficos que permitieron ilustrar los relatos periodísticos para "enganchar" a sus lectores y sutilmente persuadirlos a leer toda la información. Se publicaron notas que buscaron informar a la población sobre la relación que podría haber entre el virus del Zika y la microcefalia. Hasta la fecha de realización del estudio, solo se publicaron ciertas opiniones de que podría haber esta relación, sin embargo, no habían datos certeros sobre esta hipótesis la misma que fue comprobada en el mes de abril de 2016.

De todas maneras la información publicada sobre la microcefalia y el zika estuvo referida a ciertos aspectos o factores que determinarían que un bebé de una madre infectada podría nacer con la enfermedad y dieron datos o elementos sobre la enfermedad y sus consecuencias. Al publicar ciertos avances en torno a investigaciones en ratas para identificar la relación de la microcefalia y el Zika, es evidente que usaron encuadres del miedo y entre ellos aconsejaban que los hombres que habían sido infectados por el mosquito no tuvieran relaciones sexuales durante 6 meses.

Muchas de las conductas de salud son prácticas sociales constituidas, modificadas o eliminadas en las personas por la influencia desde los medios de comunicación (televisión, radio, cine) o de propaganda, afiches, posters, y actualmente, por los medios tecnológicos de internet y sus derivados (Urra, 2013)

En pleno siglo XXI el avance de la investigación médica ha sido extraordinario y hoy en día los lectores y los ciudadanos cada vez están más interesados en saber de sus derechos y a jugar un rol activo en la cadena informativa. Por ello los medios de comunicación tradicionales y los digitales están llamados a generar un puente para generar "formación-información ciudadana y encaminados a una relación sanidad-ciudadanos basada en la confianza mutua y en la información recíproca". (Moreno, 2010 pp.-320) en la cual el lenguaje utilizado y las formas del relato juegan un importante rol. 


\section{Gráfico n. ${ }^{\circ} 4$ \\ Encuadre de la información}

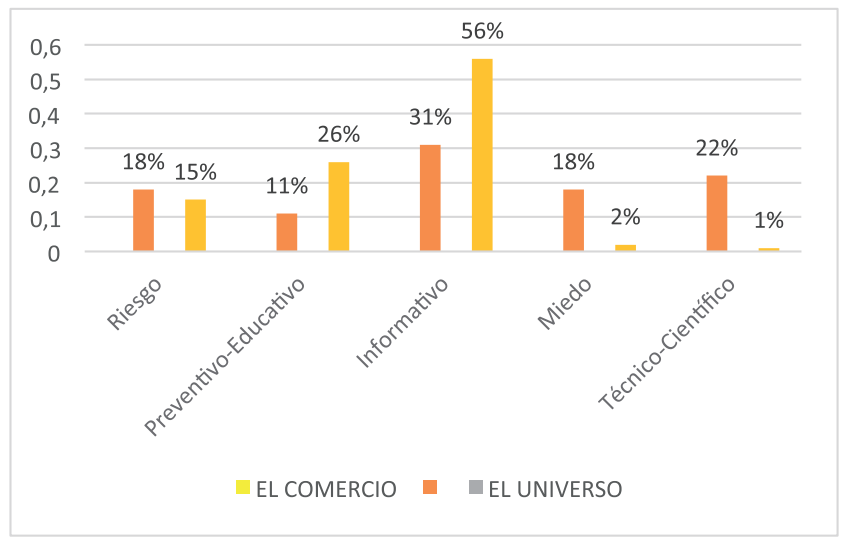

El frame o encuadre de la información periodística se refiere al enfoque que los medios de comunicación y sus redactores seleccionan para elaborar el contenido o los posibles estilos de presentación de los mensajes para sus lectores. El framing "es la idea central organizadora del contenido noticioso, que proporciona un contexto, y sugiere en qué consiste el asunto, mediante la selección, el énfasis, la exclusión, la elaboración" (Tankard citado en Sábada, 2008: pp-11).

Los encuadres pueden llevar a interpretar y concluir la realidad que los medios presentan a los lectores de manera distinta a partir de los relatos periodísticos. En esta perspectiva, se observa que el framing más usado por los dos diarios es el informativo, es decir aquel que proporciona una serie de datos y detalles de los diversos temas asociados al Zika para introducir al lector en la problemática. Es así que cuando se inició la cobertura periodística del virus, "El Comercio" inició su trabajo con una nota que anuncia la alerta epidemiológica, la posibilidad de que llegue al país y da cuenta de los antecedentes de la enfermedad y sus consecuencias así como información que la población debe conocer para prevenir su contagio. Destaca los hábitos y comportamientos que deben seguir las personas para evitar las infecciones así como el tipo de vestimenta a usar, es decir se enfocó en difundir prácticas y comportamientos para prevenir el contagio. 
En esa misma línea, "El Universo" inicia con la nota ¿Qué es el Zika? en el mismo estilo narrativo hace una reseña del origen de la enfermedad y la define conceptualmente; presenta los síntomas para identificarla así como lo que inmediatamente deben hacer las personas en caso de tener fiebre causada por el virus.

Esto también se observó en el estudio sobre la Gripe AH1N1 donde el encuadre de la prevención fue el predominante buscando desde los medios aportar con información sobre medidas de precaución que la población puede practicarlas para cuidar su propia salud y evitar la expansión de la epidemia.

Dado que la noticia "supone una valoración del acontecer diario que no solo la hace el periodista sino también la misma sociedad.." (Sábada, 2008) el marco que se aplica aquí está orientado a superar el déficit informativo que los ciudadanos tienen en relación con una nueva enfermedad. En las redacciones buscan entonces, suplir esa falencia con datos que tengan un valor de uso social en la vida diaria de las personas, en suma que sean datos útiles para que los lectores puedan tomar decisiones con base en conocimientos técnicos y científicos. Se pretende simbólicamente un acercamiento, una proximidad con los destinatarios incluyendo la presentación de testimonios de interés humano sobre personas infectadas con el virus para lograr esta cercanía que busca una cierta identificación con los actores de la noticia.

El encuadre preventivo-educativo tendiente a generar una cultura preventiva para evitar el contagio del virus cuya intencionalidad de los relatos es "educar" a la población con mensajes y contenidos claramente buscan imponer comportamientos nuevos frente a una amenaza de salud. La visiblidad de la realidad a través de los medios "tiene un valor de referencia para la experiencia personal y social" (Sábada, 2008) cuyos contenidos circulan en diversos espacios y son motivo de conversaciones, de debates, etc. Es decir, son compartidos en círculos más cercanos como la escuela, la familia, los amigos, entre otros espacios que a la vez se convierten también en instancias mediadoras y donde se resignifican los contenidos.

No hay duda que los lectores son sujetos de una realidad simbólica creada por los medios de comunicación y en la cual se crean productos simbólicos, a través de los cuales las personas comprenden el mundo. Es la visión del periodista-medio la que los lectores tienen de un determinado hecho-situación.

El encuadre del miedo es utilizado en gran medida por diario "El Universo". Los titulares que son el "enganche" para los lectores son construidos a partir de referentes que buscan generar bajo la teoría del miedo una actitud de alerta-cuidado 
en la población narrando las consecuencias del Zika y, en especial la relación entre el virus y la microcefalia.. Titulares como Pánico en Latinoamérica por el zika y su nexo con la microcefalia en bebés; Cinco casos de microcefalia por zika, en Colombia; Médicos sospechan que zika puede provocar problemas de audición o de visión en bebés (El Universo, 2016) muestran una tendencia al relato dramático.

El uso de este encuadre pudo haber provocado reacciones de ansiedad en los lectores y en mujeres embarazadas, específicamente. Acercarlos a una realidad que es compleja por sus consecuencias trae como resultado un ambiente de pánico y desasosiego. Según Sábada (2010) al definir el tipo de encuadre para construir la información periodística puede tener una influencia directa desde el reportero ya que elementos como su nivel educativo, la cultura, la etnia, las experiencias y sus creencias definen el cómo hacer la noticia y pueden influir las posibles mediaciones de valores profesionales y personales.

A la fecha de cierre de la recolección de la información para este estudio no se había confirmado la relación entre el Zika y la microcefalia en bebés, se adelantaron algunas informaciones en relación con el tema, producto de investigaciones que estaban en proceso y que ya daban algunos indicios sobre este vínculo. Es el 14 de abril de 2016 que se anunció la noticia a través del Centro de Control de Enfermedades de los Estados Unidos, (CDC). "Hemos confirmado ahora lo que las crecientes pruebas sugerían. Ahora está claro que el virus causa microcefalia", dijo el director del CDC, Tom Frieden, respecto del estudio realizado por su equipo y publicado en el New England Journal of Medicine. (Ayuso, 2016).

"La narrativa de riesgo perpetrada por los medios se apoya, en gran medida, en declaraciones de fuentes oficiales y expertos técnicos" (Waisbord, 2011). Esto con el fin de argumentar y generar credibilidad y confianza en el público para que tomen medidas de precaución, por lo cual ponen énfasis en un marco interpretativo de peligro, aun cuando el mismo podría ser de doble filo ya que el miedo genera angustia y ansiedad en las poblaciones consideradas vulnerables al no tener los mecanismos y herramientas para enfrentar una epidemia.

Cerca de una cuarta parte de las notas de "El Comercio" usa un encuadre científico-técnico que está basado en declaraciones e información generados por autoridades locales como la ministra de Salud Pública del Ecuador, Margarita Guevara; autoridades regionales como la directora general de la Organización Mundial de la Salud, Margaret Chan; representantes de centros de investigación de fuera del país, que dan cuenta del proceso epidemiológico de la enfer- 
medad así como los procesos de investigación que se desarrollan para establecer y confirmar la relación entre el Zika y la microcefalia en bebés y las medidas de precaución a tomar en cuenta por parte de los ciudadanos.

En definitiva, esta selección de los marcos que los diarios utilizan predominantemente se limitan a la coyun- tura y una vez superada la alerta, la información decae notablemente lo que la convierte en una "epidemia silenciosa" aunque no esté en las portadas de los medios, la epidemia no desaparece. Una muestra fehaciente de ello es el rebrote en estos días de la gripe $\mathrm{A}(\mathrm{H} 1 \mathrm{~N} 1)$ que se creía superada.

\section{CONCLUSIONES}

El espacio otorgado a la epidemia del virus Zika fue mínimo pese a la gravedad de la misma y al impacto mediático que tuvo, no mereció espacios importantes en los diarios ecuatorianos, al ser una publicación episódica enmarcada en el género noticia. Los dos diarios publicaron un total de 71 notas informativas en cinco meses, con un promedio de 0.47 notas por día. Esta es una tendencia constante al publicar información solo el momento en que la situación es más crítica para luego pasar a segundo plano la información y finalmente desparecer del ámbito periodístico. Los teóricos de la comunicación llaman a esto ciclo episódico y al cual la información está asociada.

Los diarios generaron información con alta referencialidad, buscando una pluralidad de fuentes, pese a la ausencia de científicos, para proveer de datos y dar orientación a los ciudada- nos sobre cómo prevenir el contagio del virus. Sin embargo, la narrativa de percepción de riesgo, del miedo y consejos orientados a influir en la modificación de comportamientos de los ciudadanos fue reiterativa. Los titulares y el texto de la información están cargados de significados tendientes a evitar el contagio mostrando como referentes las situaciones dramáticas de otros países en los cuales la realidad de la epidemia fue muy crítica debido a la cantidad de contagiados. Los medios respondieron a una dinámica de la coyuntura que obedecen a riesgos tangibles y a ciclos mediático-episódicos.

La prensa analizada usó un enfoque predominantemente informativo al ofrecer datos, cifras, indicadores, consejos, información científica, testimonios y otros de interés de los lectores. Es decir, puso a disposición información gene- 
rada fuera del país donde la epidemia avanzaba de forma alarmante y los contagiados se multiplicaban a gran velocidad, en tanto los centros de investigación se centraron en la búsqueda de una vacuna contra el virus. La selección de los marcos fue acertada ya que posibilitó que la población tuviera oportunamente información que sería usada en la toma de decisiones de su vida cotidiana para el cuidado de su salud. 


\section{BIBLIOGRAFÎA}

Ayuso,S. (14 de abril de 2016).www.elpais. com. obtenido de http://internacional/2016/04/13/estados-unidos/1460581074_417966.html

Cevallos, M. y Massarani L. org.(2011). La pandemia del miedo: Telediarios y la gripe A(H1N1) en Ecuador y Brasil. Quito: Digital Center.

El Comercio (24 de febrero de 2016). www.elcomercio.com. Obtenido de http://www.elcomercio.com/ actualidad/zika-advertencia-empeorar-brasil-oms.html

Joubert, M. (22 de septiembre de 2004). ¿Como me torno um "especialista" em midia? Guía de Divulgacao Cientifica, 42. Río de Janeiro, Brasil: $\mathrm{s} / \mathrm{d}$.

Loewy, M. (2011). ¿Lo importante es la salud? En M. y. Petracci, Comunicación y salud en la Argentina (págs. 153-170). Buenos Aires: La Crujía.

Maguina, C. (2016). Zika, la nueva enfermedad emergente en América. Revista Médica Herediana.

Ministerio de Salud Pública, MSP. (26 de octubre de 2016). ENFERMEDADES TRANSMITIDAS POR VECTORES ZIKA VIRUS. Obtenido de Ministerio de Salud Pública: http:// www.salud.gob.ec/wp-content/ uploads/2015/12/GACETA-ZIKA-SEM42.pdf
Moreno, P. (2010). Periodismo biomédiCo, nuevos contenidos mediáticos. Estudios sobre el Mensaje Periodístico, 319-330.

OPS/OMS. (08 de agosto de 2016). http:// www.paho.org/. Obtenido de http://www.paho.org/

OPS/OMS. (17 de noviembre de 2016). ZIKA Actualización Epidemiológica Regional de la OPS (Américas) 17 de noviembre de 2016. Obtenido de http://www.paho.org: http://www.paho.org/hq/index. php?option=com_content\&view $=$ article\&id $=11599 \&$ Itemi$d=41691$ \&lang $=e s \mid$

PAHO/WHO. (17 de noviembre de 2016). www-paho.org. Obtenido de http://www.paho.org/hq/index. php?option=com_docman\&task=doc_view\&ltemid=270\&gi$d=36938 \&$ lang $=e s$

Piñuel, J. (2002). Epistemología, metodología y técnicas del análisis de contenido. Estudios de Sociolingüística 3, 1-42.

Polino, C., Chiappe, D., \& y Fazio, M. (2006). Análisis de la oferta informativa sobre ciencia y tecnología en los principales diarios argentinos. Observatorio de Ciencia, Tecnología e Innovación Productiva de la SeCyT. Buenos Aires: http:/www.obser- 
vatorio.mincyt.gov.ar/docs/percep/estudio_medios.pdf.

Román, V. (2011). El rol del periodista ante la comunicación de enfermedades y su impacto. En M. y. Petracci, Comunicación y salud en la Argentina (págs. 171-184). Buenos Aires: La Crujía.

Sábada, T. (2008). Framing: el encuadre de las noticias. El binomio terrorismo medios. Buenos Aires: La Crujía.

Tankard, J. (1991). Media Frames. approaches to conceptualization and Measurement. Ponencia presentada en Comunication Theory and Metodology Division Associatio for Education in Journalis and Mass Communication Convetion. $\mathrm{s} / \mathrm{n}$. Boston.

Torres, M. (2016). Virus Zika, una nueva epidemia en puerta. Revista Biomédica $2, \mathrm{~s} / \mathrm{n}$.
Universo, E. (26 de febrero de 2016). www.eluniverso.com. Obtenido de http://www.eluniverso.com/noticias/2016/03/15/nota/5467656/ cuba-reporta-primer-caso-zika-transmitido-isla

Urra, E. e. (2013). El análisis del discurso como perspectiva metodológica para investigadores de salud. Enfermería Universitaria.

Viñuela Benéitez, M. y. (2016). Virus Zika y gestación. Obstetricia y Ginecología. Revista Oficial de la Sociedad Española de Obstetricia y Ginecología, 104-11.

Waisbord, S. (2011). Cuando la salud es titular: dengue, gripe A y ciclos "mediáticos epidémicos". En P. y. (comps), Comunicación y salud en la Argentina (págs. 185-200). Buenos Aires: La Crujía. 
